\title{
EL TRAZADO VITRUVIANO COMO MECANISMO ABIERTO DE IMPLANTACIÓN Y AMPLIACIÓN DE LOS TEATROS ROMANOS
}

\author{
POR \\ SALVADOR LARA \\ Arquitecto. Universidad Politécnica de Valencia. España \\ Departamento de Composición Arquitectónica
}

\begin{abstract}
RESUMEN
En base a su trabajo monográfico sobre el teatro de Sagunto, el autor identifica, por el análisis directo de las obras de fábrica, diferentes fases constructivas que suponen ampliaciones sucesivas de una primera implantación romana del teatro.

Relacionándolas por medio de su correspondencia con el tipo definido por Vitruvio, se descubre el sistema que utilizaron los constructores romanos para ampliar el edificio teatral saguntino que había, ya previamente, obtenido una primera implantación basada en un trazado vitruviano ortodoxo.

Desde esta perspectiva se contemplan los tres tipos de teatros romanos propuestos por D. Small en su artículo de $A J A$ de enero de 1983 como tres estadios de la evolución del mismo tipo teatral y el trazado de F. Sear aparecido en esta misma publicación en abril de 1990 como un caso particular del sistema general que se propone aquí como regulador de la evolución de las estructuras teatrales romanas.

La hipótesis que se presenta a continuación, como propone una metodología generalizable para el estudio de los teatros romanos, se comprueba en aquellos de Hispania de los que se dispone de planimetría fiable (Acinipo, Itálica y Segóbriga....) identificando la validez de su planteamiento.
\end{abstract}

\section{SUMMARY}

On the basis of the monographic work about the roman theatre of Sagunto (Spain), the author identifies, from the direct analysis of the ruins, the different construction phases that compose the succesive developments of the original roman implementation.

Relating each of the phases with the type defined by Vitruvio, we find the method that the roman constructors used to enlarge the initial theatre of Sagunto which had been designed on the orthodox basis of the vitruvian model. 
From this point of view are contemplated the three types of roman theatres proposed by D. Small, in his article published in A.IA of January, 1983, as three states of evolution of the same theatre type, and the layouts of F. Sear appeared in the same publication in the issue of April 1990 as a particular case of the general method that is proposed here as the regulator of the evolution of the structures of the roman theatres.

The hypothesis that is presented next, so much that it proposes a general method for the study of roman were we have found reliable cartography of Acinipo, Italica and Segobriga, showing its validity.

\section{INTRODUCCIÓN}

La mayor particularidad del edificio teatral romano, a partir del siglo I a. C., es precisamente la existencia consciente de unas reglas que organizan su desarrollo: los trazados reguladores del Tratado de Vitruvio. Estas reglas no fueron, entonces, deducidas del análisis de múltiples y variados edificios y después elevado a generalización, sino que eran conocidas previamente a la gran mayoría de la edificación de los teatros.

En «Hispania», cuanto menos, la relación fue clara y directa. Vitruvio escribe sus «Diez libros de Arquitectura" y muy pocos años después, Augusto organiza la construcción de la gran mayoría de los teatros que hoy contemplamos. Suponer la relación directa en la primera implantación y génesis de los edificios teatrales, no parece aventurado. Así, la propuesta de este trabajo, consistente en el análisis de la existencia y aplicación de los trazados vitruvianos en los teatros romanos y particularmente en el de Sagunto, puede resultar una útil herramienta para facilitar su comprensión.

\section{EL TRAZADO DE VITRUVIO SEGUN VITRUVIO}

Realmente decir esto resulta aventurado ya que el legado de su tratado, como sabemos, es a través de múltiples copistas y desconocemos hoy hasta qué punto está alterado. Existe sin embargo un consenso entre todas las traducciones consultadas, con respecto a los trazados que resumo aquí, extraidos del capítulo sexto: «De la forma del theatro» que nos presenta en su tratado. Así pues inicialmente se traza la circunferencia completa de la orchestra sobre un lugar plano. El diámetro de la circunferencia no viene determinado, es elegido por el arquitecto. A continuación se inscriben en su interior 4 triángulos equiláteros produciendo las siguientes correspondencias:

— La base del triángulo paralela a la escena y más próxima a ella, define la alineación del frontscaena.

- Una paralela a esta línea por delante divide el pulpitum del proscaenium y delimita el espacio de la orchestra en el interior de la cávea.

Aquí los traductores difieren entre sí de modo sustancial variando el lugar de situación de la paralela al frente de la escena respecto de la orchestra.

- Los 7 ángulos que pertenecen al semicírculo de la cávea determinarán sus scalariae en el primer círculo. Los tramos superiores alternarán con los bajos. Los otros 5 ángulos señalarán la composición de la escena. Enfrente del central, la puerta real y de los 2 contiguos, las hospitalia. 
En resumen, el círculo de la orchestra, la inscripción de los 4 triángulos, la situación del frente de escena, las subdivisiones de la cávea y la posición central de la valva regia fueron fácilmente asimilados y reproducidos. Por contra, la indeterminación de la línea del pulpitum provocaba desplazar los aditi y la posición de las valvas hospitalia admitía algunas variaciones.

\section{LA APLICACIÓN DEL MODELO VITRUVIANO}

Si los trazados que propuso el arquitecto romano en el siglo I a. .C., fueron aplicados a la construcción de los teatros y hasta que punto, ha sido un tema ampliamente debatido. Todavía hoy no ha sido cerrada la investigación y se siguen publicando trabajos al respecto. A menudo una recomendación que el autor había dado a sus contemporáneos para que adaptaran las indicaciones del tratado ha sido la justificación dada por los estudiosos modernos para afirmar que los arquitectos abandonaron las reglas allí expuestas. Pero analicemos detenidamente los textos para descubrir y reinterpretar su significado:

Pero no en todos los theatros pueden responder las medidas a todas razones y effectos, sino que cóuiene considerar el architecto, con que proporciones se ha de seguir la medida, y con $q$ razones deuaser templada la obra cóforme a la naturaleza del lugar, y a la grandeza de la obra, porqay algunas cosas, las quales en chico y grande theatro, es necessario que se hagá de vna misma grandeza por razon del vso, assi como las gradas, los diazomatos, que son los patios, los pluteos, que son los llanos, los caminos, subidas, entradas, pulpitos, los tribunales y sillas, y si otras cosas ay que entreuengan, en las quales la necessidad fuerça a apartarnos de la medida, porque el vso no fe impida. Tambien conuiene si ay falta de materiales, como de marmol, o de madera, y de las demas cosas que se aparejan para la obra, quitar, o añadir algun poco, con tal que no se disforme, ni parezca feo, antes con acuerdo y juyzio. Esto se entiende, si el architecto fuere hombre sabio, y tuuiere vso, y experiencia, y no careciere para esto de ingenio, $y$ solercia [Vitruvio, 1582, pág. 68].

Fijándonos en el contexto advertiremos que Vitruvio escribe esto en el capítulo VII «Del techo del portal del theatro", después de haber modulado la dimensión de la escena y sus órdenes arquitectónicos. Los trazados reguladores los había explicado ya en el capítulo anterior (VI) De la forma del theatro, en el que no hacía ninguna concesión a la variación o libertad personal. Por otro lado, en el capítulo VI, se establecen los trazados en base a relaciones geométricas posicionales, colocando los elementos en su contexto y en relación de vecindad con sus colindantes. Por contra en el capítulo VII, se define la dimensión de elementos conocidos y no exclusivos del edificio teatral (podio, pedestales, columnas, capiteles, arquitrabes, etc.). Por medio de modulación respecto de la orchestra y a base de relaciones numéricas $(1 / 2,1 / 6,1 / 5$, etc.), se dan medidas de los diferentes elementos.

Si reelemos el texto vitruviano, veremos que aconseja ajustar las medidas para «ser templada la obra». Esta práctica, lógica para adecuar las órdenes a las dimensiones del teatro, era necesaria si tenemos en cuenta que no hay dos teatros en el mundo romano de las mismas dimensiones. Sin embargo un trazado geométrico es «amétrico». Las normas vitruvianas podían crecer o disminuir sin variar en lo más mínimo su significado. No tienen relación alguna con las dimensiones del teatro ya que no incluyen ni medidas, ni límite alguno que determine su lindes externos. Así pues, el autor aconsejaba ajustar las medidas de los elementos, pero se mantenía 
inflexible en sus trazados; aquello lo que significa su geometría. Con ello Vitruvio conseguiría que, aunque se variaran las dimensiones de los teatros, se mantuviera su aspecto interior constante por medio de la relación posicional de sus elementos principales.

Otro asunto aparte será conocer si los arquitectos romanos que trazaron los teatros obedecieron o no al autor del tratado.

\section{LA INVESTIGACIÓN MODERNA}

Muchos autores han tratado este tema. De entre ellos merecen destacarse algunos por su especial interés:

1961. Margaret Bieber en su obra The history of the Greek and Roman theater [Bieber, 1961, pág. 186], concluye su análisis tipológico de los teatros romanos diciendo: «La forma de los teatros construidos al final de la república y en el período de Augusto, debió ser la que Vitruvio Pollion conocía cuando describió, al rededor del 13 al 16 a. C., el teatro Romano y recomendó su imitación.»

La autora se refiere al modelo vitruviano como extraido de la práctica constructiva empleada entonces. Por lo tanto, el sistema no sólo provenía del tratado sino también de la realidad edilicia y por ende, sus ejemplos eran cuantiosos. Vitruvio simplemente lo recogió. Demostrado queda pues que se aplicó, por lo menos en estos períodos.

1965. P. C. Hammond en The Excavation of the Main theater at Petra [Hammond, 1965, págs. 64-65], plantea una variación respecto del trazado vitruviano, que detecta en su trabajo sobre Petra. El autor advierte posiciones del frontscaena más retrasadas que la línea de la base del triángulo equilátero principal de la orchestra, que le impiden relacionar los tres vértices centrales con las tres valvas. Estas se encuentran más separadas que aplicando los trazados.

Su propuesta se basa en la utilización exclusiva, para la escena, del triángulo equilátero principal (el delimitador del frontscaena), pero esta vez para obtener la posición de las hospitalia. Prolongando sus lados oblícuos e intersecando con la alineación real de la escena, encontramos la posición de las puertas. Mantiene la valva regia en el eje vertical (figura 1).

Resulta difícil pensar que la situación del muro del frontscaena - primer y más importante resultado de los trazados - fuera abandonando por los romanos tan fácilmente, manteniendo por otro lado la necesidad de trazar el triángulo principal, para situar algo más accesorio como las hospitalia.

1983. David B. Small, publica en American Journal of Archaelogy, su artículo titulado «Studies in Roman Theater Desing». En su trabajo, niega que la mayoría de los teatros se construyeran sobre los trazados vitruvianos y por consiguiente invalida la hipótesis de Hammond como deducida por modificaciones de aquellos. «El sistema de Hammond está basado sobre el método vitruviano, cuya relevancia debe ser seriamente cuestionada [Small, 1983, pág. 65].

El trazado, según Small, se ajustaba más o menos bien a la cávea, pero no a la escena. Para su trabajo, va a clasificar tres tipos de teatros con relación a la configuración de su frontscaena.

1. Con scaenae frons recta y columnata rectilínea.

2. Con valva regia semicircular y las laterales rectangulares.

3. Con tres valvae semicirculares. 


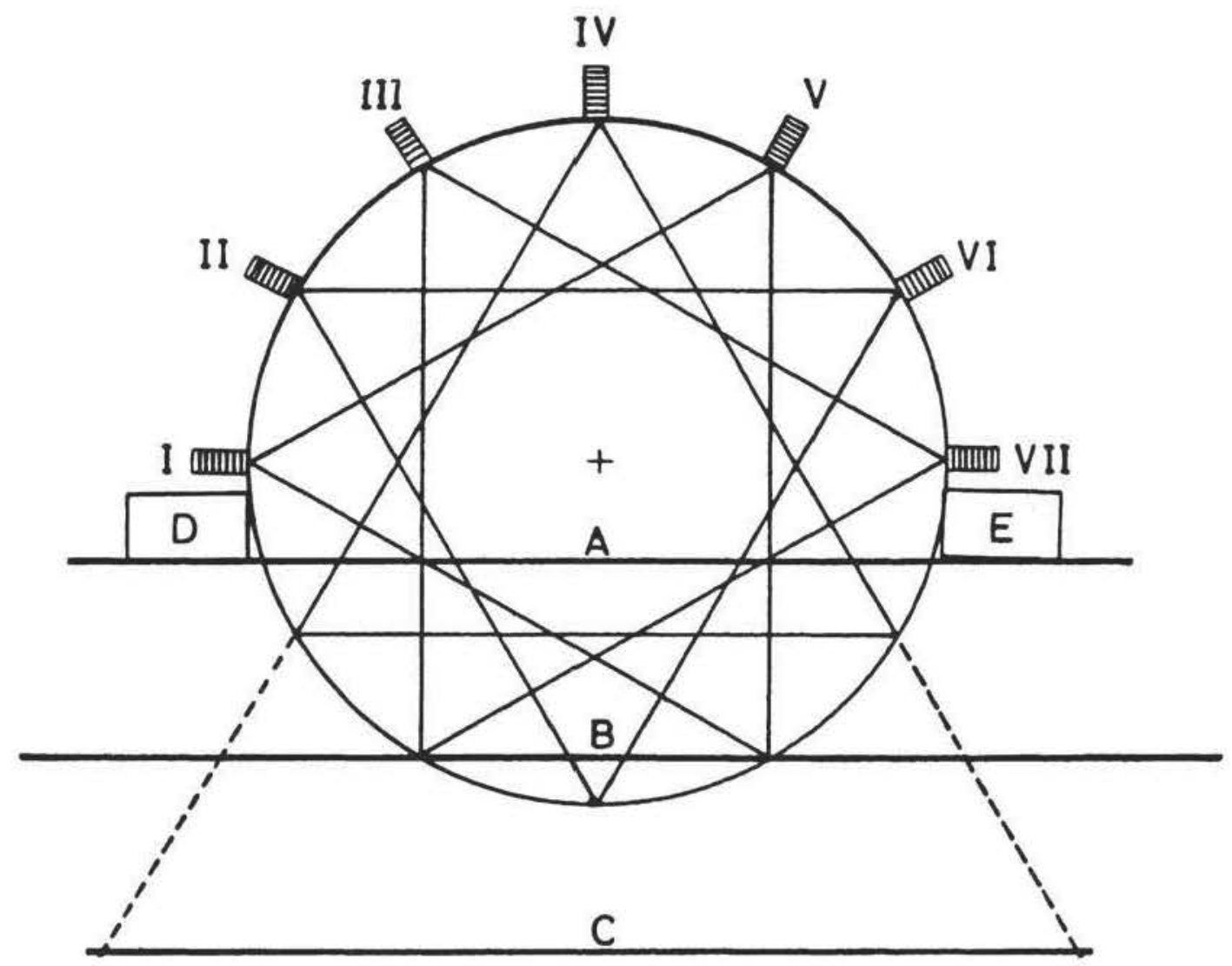

Figura 1.-Trazado P. C. Hammond. A, línea finitio proscenii; B, línea scaenae frons; $\mathrm{C}$, línea muro postcaenium: $\mathrm{D}$, vomitorium dextrum; $\mathrm{E}$, vomitorium sinistrum; I a VII, itinerae.

Para el grupo primero, establece una cronología desde el final de la República hasta la mitad del siglo II d. C. Acepta que su implantación se realiza con trazados vitruvianos, pero que su exactitud debería ser revisada. [Small, 1983, pág. 61] Incluye aquí teatros tan diferentes como Ostia, Pompeya, Casino, Aspendos y Gerasa.

Es partidario de suponer, para el segundo grupo, - en contra de Bieber y otros-que aunque este tipo de escenas se atribuyan a reformas posteriores, sus trazas son originales: «Hay persuasivos argumentos para afirmar la originalidad del diseño. Un dato derivado de la decoración de los scaenae frons no debe ser aplicado al edificio escénico entero» [Small, 1983, pág. 63].

De este modo, el autor propone que, si la valva semicircular proviene de una concepción de nueva planta, podríamos descubrir un trazado que la contemple. Ya que por el contrario si aparece con una reforma parcial referente al cuerpo escénico ello sería más difícilmente justificable. Agrupa teatros como Mérida, Pompeyo, Orange, Palmira, Dougga, Petra, etc., cronológicamente situados entre Augusto y la primera parte del siglo II d. C.

Por último en los teatros con tres valvas semicirculares aparecen como elementos nuevos el traslado del frontscaena, y el espaciado mayor entre las hospitalia. Cronológicamente situados 
entre la segunda mitad del siglo II d. C. y el final del III. Leptis Magna, Sabratha, Corintio, Lyon y Sagunto, se presentan aquí.

La disposición entre las partes (Orchestra-valvae-scaena-aditi) en los tipos 2 y 3, parecen no guardar relación directa de procedencia con los trazados vitruvianos. Esto da pie a Small para plantear la existencia de un trazado oculto que él descubre, con el que se edificaron los teatros de los grupos 2 y 3 .

Pero en lugar del sistema Vitruviano, el diseño de estos teatros, responden al siguiente modelo: (figura 2).

- Se inicia igualmente por una circunferencia que ocupe la orchestra.

- Trazar el diámetro del círculo que separa cávea y escena. (A-B).

- Sobre la circunferencia el arquitecto coloca las dos columnas de la valva regia ( $\alpha$ y $\beta$ ).

- Traza el diámetro DC perpendicular a AB.

- Sobre este eje DC, el arquitecto dibuja un círculo que le define el tamaño y la posición de la valva regia.

- Dos pasos son necesarios para buscar las hospitalia:

- Trazar la perpendicular (EF) a DC y tangente a la orchestra, donde se situará el frontscaena.

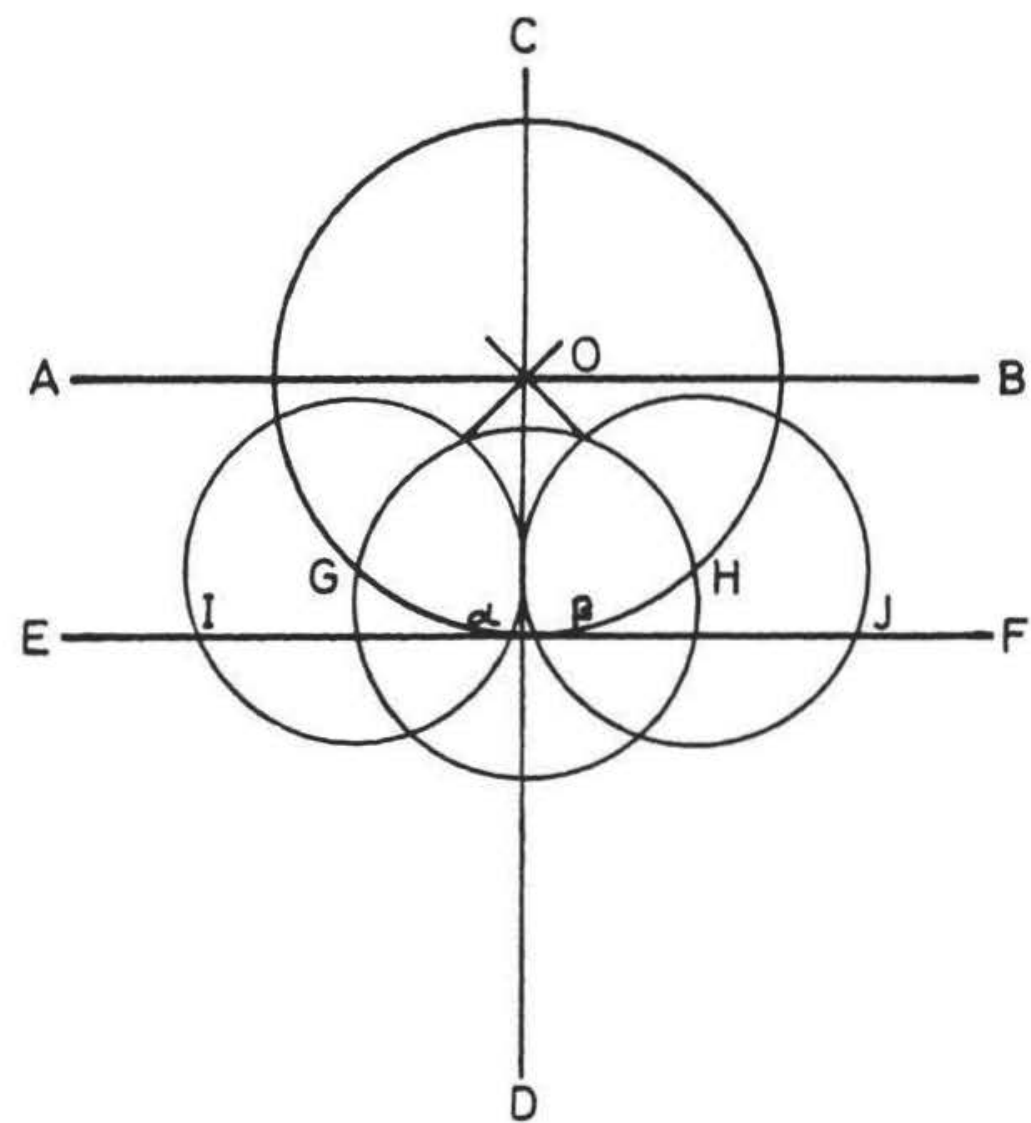

Figura 2.-Trazado D. Small. 
- Desde los puntos de intersección $(\mathrm{G}, \mathrm{H})$ entre las circunferencias de la valva regia y de la orchestra, se trazan dos nuevos círculos que producen dos intersecciones $(\mathrm{I}, \mathrm{J})$ con la línea EF del frente de la escena, donde se colocarán las hospitalia.

Este curioso sistema, casi exclusivamente a base de circunferencias, necesita precisiones del autor referentes a:

Adaptabilidad: Reclama la posibilidad de variaciones y ajustes: «La aplicación de cualquier sistema en arquitectura no puede ser completamente uniforme.» [Samll, 1983, pág. 87].

Variabilidad: Las circunferencias con centro en $\mathrm{G}$ y $\mathrm{H}$, pueden optar por tener dos radios: o bien el de la valva regia o el de la orchestra, a elegir por el arquitecto.

Globalidad: Este sistema plantea la situación de los elementos escénicos, sin contemplar la cávea. Para ello, Small propone un sistema mixto. "Algunos arquitectos debieron haber estado usando dos sistemas de diseño. El método vitruviano para determinar la situación de las escaleras, mientras nuestro sistema propuesto determinó el diseño del escenario.» [Small, 1983, pág. $68]$.

Y por último, la frontscaena no siempre viene situada sobre la línea $\mathrm{EF}$, tangente a la orchestra, sino que a menudo sobre todo en los ejemplos africanos (grupo 3 ) se aproxima al postscaenium, lo que representa un pormenor interesante sobre el que volveremos más adelante.

\section{ANÁLISIS DE LA PROPUESTA DE SMALL}

D. Small plantea un sistema, al margen que original, profundamente contradictorio internamente. El autor supone tres tipos de teatro, de nueva planta con personalidad tipológica propia y derivados de diferentes trazados. Sin embargo, después propone la utilización de dos esquemas diferentes: uno para la cávea y otro para la escena. Si su propuesta se refiere exclusivamente al edificio escénico y la principal característica del edificio teatral romano es la unidad entre las partes, es indudable que nos hallamos ante una actuación parcial en el teatro. Es decir, el autor propone un esquema regulador para reformar escenas.

Además el sistema plantea demasiadas elecciones para un trazado regulador: La orchestra, la posición de las columnas de la valva regia, la situación del frontscaena, el diámetro de la valva regia, son variables a elegir por el arquitecto. Si a esto añadimos la posibilidad de elegir la circunferencia regia o de la orchestra para fijar las hospitalia, nos daremos cuenta que tal ambigüedad hace que el sistema ajuste en prácticamente cualquier edificio teatral. Cinco variables en un trazado para definir la escena parecen demasiadas frente a una única variable - diámetro de orchestra - del trazado vitruviano, para definir el conjunto del edificio. Cuesta trabajo pensar que un arquitecto romano necesitara tal grado de libertad al construir un teatro.

Por fin, para trabajar y obtener conclusiones sobre trazados en arquitectura, la primera condición indispensable es una exacta y detallada cartografía de cada monumento. D. Small utiliza, como a menudo nos vemos obligados a hacer todos, las reproducciones gráficas de los teatros provenientes de textos generales, que presentan un insuficiente grado de definición. Así en el caso de Sagunto, que más intensamente se ha estudiado aquí, Small presenta los siguientes datos en su tabla 3 elaborados a partir del plano que recoge del texto de Hanson [Hanson, 1959, lám. 35]. 
- Datación: mitad del siglo II d. C (situándose hoy en los primeros años de nuestra era).

- Relación entre los diámetros: regia-orchestra $=0,46$ (siendo la real 0,55 ).

- Coloca el aditus en la parte de la escena respecto del diámetro, cuando realmente coincide con el eje.

1990 Frank B. Sear, en la misma publicación periódica "AJA», escribe su artículo Vitruvius and Roman Theater Design, donde plantea la demostración de que los arquitectos del temprano Imperio modificaron el trazado vitruviano sin abandonar su uso. [Sear, 1990, pág. 249].

Inicia su trabajo detectando las disfunciones que respecto del tratado de Vitruvio presentan los teatros. Para ello va a centrar su explicación alrededor del teatro emeritense: «En la mayoría de los teatros, al menos de las provincias del oeste, las puertas están separadas más ampliamente que la prescripción vitruviana y la scaenae frons se sitúa en la tangente del círculo de la orchestra. [Sear, 1990, pág. 252].

F. Sear, reconoce cierto grado de aproximación en el sistema que propuso Hammond, aunque no siempre coinciden sus puntos con los de las posiciones reales de las hospitalia. Después de descalificar a Small, añade a continuación: «Es en las escalinatas donde está la clave del diseño del teatro.» [Sear, 1990, pág. 253-254].

Definiendo después su interpretación y adaptación del trazado: (figura 3).

- El arquitecto dibujó el círculo que iba a ser su orchestra.

- Trazado el diámetro horizontal (CD), el aditus puede colocarse en cualquiera de sus tres posiciones: del lado de la cávea, de la escena o coincidiendo su eje con el diámetro $\mathrm{CD}$. En la época Imperial, se utilizaron generalmente las dos últimas.

- Una paralela al diámetro y tangente en la parte inferior de la circunferencia, determina la línea del frontscaena (NP).

- Se trazan los 4 triángulos creando 12 intersecciones en la circunferencia.

- Estos puntos, determinan las escaleras, cuya posición debe corregirse en función de que el aditus ocupe o no espacio del semicírculo de la cávea.

- Si la escena es tangente a la orchestra, las hospitalia quedan fuera del círculo. Por ello, se deben proyectar desde la circunferencia hacia el exterior «del mismo modo como se hizo en el lado de la cávea» [Sear, 1990, pág. 255], o sea radialmente (QR).

Este sistema de aplicación directa para los teatros que dividen su cávea en 6 cunei (Mérida, Corintio, Verona...), es adaptado por el autor a los que dispone de 5 y 4 , inscribiendo en la orchestra 2 pentágonos o 2 cuadrados respectivamente.

\section{ANÁLISIS DE LA PROPUESTA DE SEAR}

La propuesta general es altamente interesante y supone una leve adaptación del modo de trazar la posición de los elementos de la escena. Su acierto viene avalado por la práctica y se ajusta a un gran número de teatros. Los puntos del trazado, coinciden bastante fielmente con la posición de los elementos de gran cantidad de teatros que estudia el autor. Sin embargo es interesante profundizar en algunos extremos acerca de:

- La direccionalidad de los vértices:

El trazado vitruviano sirve para marcar posiciones de los elementos, no necesariamente di- 


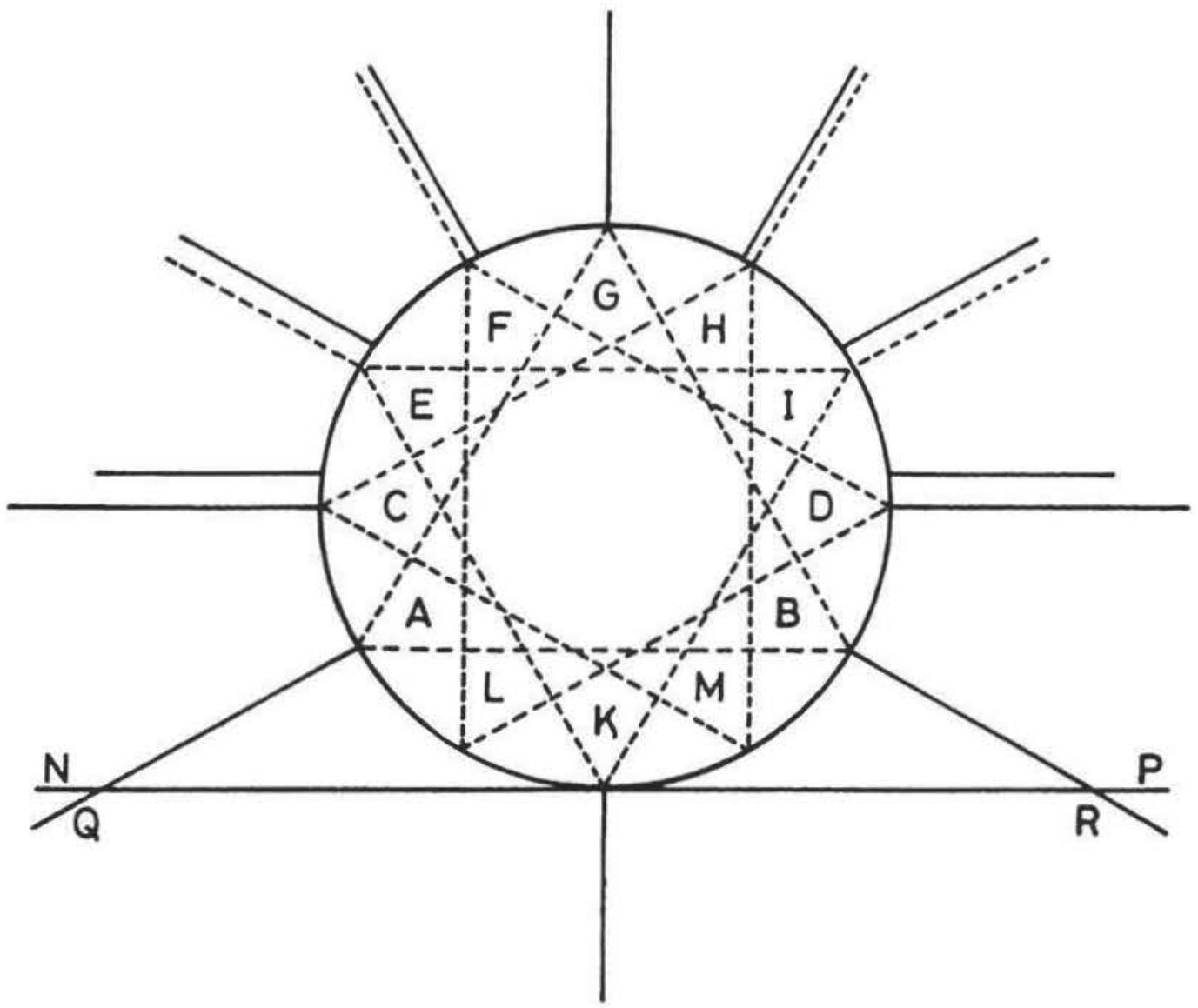

Figura 3.-Trazado F. Sear. Método general (corrección cavea).

recciones u otras características. Los 5 vértices superiores, indican la posición de las escaleras. Su dirección viene definida por la cávea que al ser circular, las necesita radiales, con el fin de subdividir uniformemente el conjunto. Por el contrario, los 5 puntos inferiores, se corresponden con un edificio lineal: la escena. Su dirección deberá venir condicionada por una ortogonal o paralela respecto del edificio escénico. Así se afirma también en el tratado de Vitruvio, al decir que las valvas estarán enfrentadas con sus correspondientes vértices. Los dos vértices de los aditi constituyen el elemento ambiguo de transición entre la estructura radial de la cávea y la ortogonal de la escena, y pertenecen a las dos partes, además de tener una personalidad propia.

Esta concepción hace difícil de aceptar, desde un punto de vista teórico, que algún elemento de la cávea adopte estructura ortogonal, tanto como que algún otro de la escena, se defina irradiando desde el centro como plantea F. Sear en su sistema.

- Las variaciones tipológicas:

Las soluciones adaptadas para teatros con 5 y 4 cunei, son más difícilmente asimilables:

La primera inscribe 2 pentágonos que representa una figura trazable con dificultad, y de uso nada extendido en el mundo romano. Por otro lado, no aparecen representados ni la escala, ni la valva regia, ni existe correspondencia entre el número de vértices con la cantidad de elementos a situar. 
La segunda, de 2 cuadrados, se muestra certera para pequeños teatros, incluso odeones, edificios más tardíos, no definidos por Vitruvio y con mucha variación tipológica. Su aplicación, si se produjo, necesitaría de una explicación más detallada por parte del autor, ya que hoy no resulta convicente (figura 4).

En cualquiera de los dos casos, existe una alteración importante del modelo vitruviano, pasando de disponer 12 vértices en el original a 10 u 8 en los siguientes. Tal variación, trasciende de la mera adaptación para adentrarse en la definición de esquemas tipológicamente diversos del romano. Recordemos que el mismo Vitruvio, para definir el teatro griego, vuelve a utilizar 12 puntos, aunque por medio de una transformación de sus proporciones propiciada por la inscripción de 3 cuadrados.

\section{APLICACIÓN DE LOS TRAZADOS A SAGUNTO}

Definición del ámbito del círculo de la orchestra:

La posibilidad de disponer gradas o niveles de asiento en su interior creó una cierta ambi-

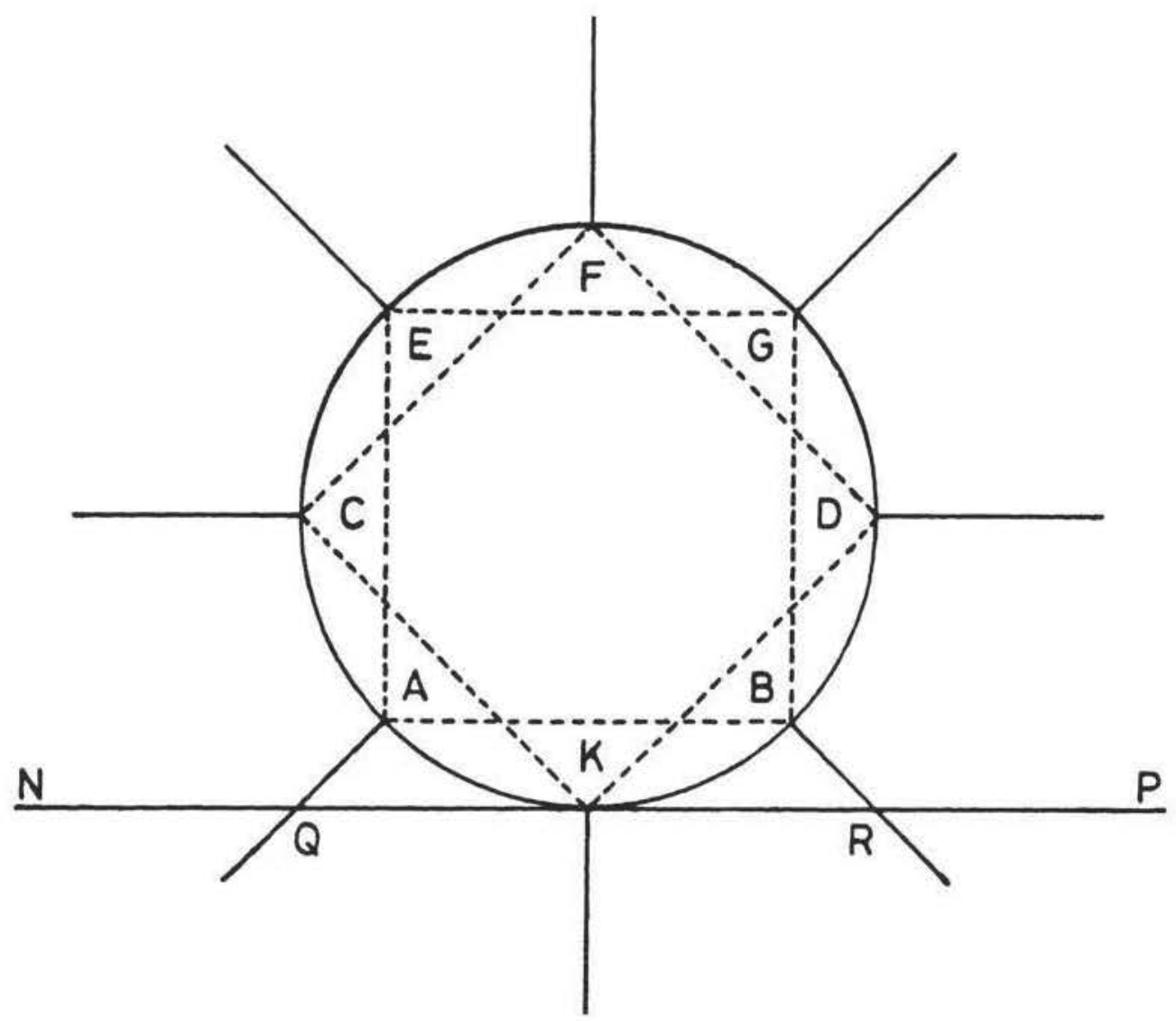

Figura 4.-Trazado F. Sear. Cuatro cunei. 
güedad en la definición del espacio de la orchestra. Si a esto le añadimos la libertad total del arquitecto para elegir el número y las dimensiones, los resultados son tan variables como se presentan en la actualidad. Por ello los autores que han tratado los trazados de los teatros eligen a voluntad la circunferencia a utilizar para definir la orchestra, reconociendo la ambigüedad de su propia definición. [Small, 1983, pág. 58]. Así Small para Mérida, incluye una grada en su orchestra, ninguna en Thubursian y Corinto, todas en Forum Julii y todas con la praecinctio en Dougga y Vasio. Sear por su parte, abarca todas con la praecinctio en Arus, sin la praecinctio en Volterra y ninguna en Mérida.

\section{TRAZADOS TEÓRICOS COMPARADOS}

Representemos sobre un caso real los tres trazados propuestos por los autores y observemos lo que sucede en su aplicación al ejemplo saguntino por medio de su análisis comparado:

\section{Hammond: (figura 5)}

La prolongación del triángulo principal intersecciona con el frente de escena en el punto exterior de la supuesta posición del final de las valvas hospitalia. Donde debería estar el centro acaba la circunferencia.

El frente de escena se produce en un punto más retrasado del Vitruviano y coincide con la tangente a la circunferencia de la orchestra.

El desajuste en la situación de las hospitaliae se aproxima a los 4 metros.

Sear:

Método general: (figura 5)

Se demuestra más eficaz. Si bien en la cávea sólo coinciden la escala regia y las extremas del diazoma, en la escena nos sitúa el frente de escena y los centros de las dos valvas hospitalia. La longitud de la escena es mayor del doble del diámetro de la orchestra, sin embargo esta es la medida que hay entre los extremos exteriores de la caementicia de las valvas hospitalia.

Método para cuatro cunei: (figura 6)

Si aplicamos la adaptación planteada por el autor, no observaremos más coincidencia que los dos ejes principales. Obviamente éstos coinciden siempre con los aditi y valva-escala regia. El resto se demuestra inválido.

\section{Small:}

Aunque si el trazado del autor inglés ha sido aquí cuestionado teórica y prácticamente debemos, sin embargo, reconocerle algún acierto o proximidad con la realidad en los ejemplos que dibuja en su artículo, e incluso con el saguntino (ver la figura 7). 


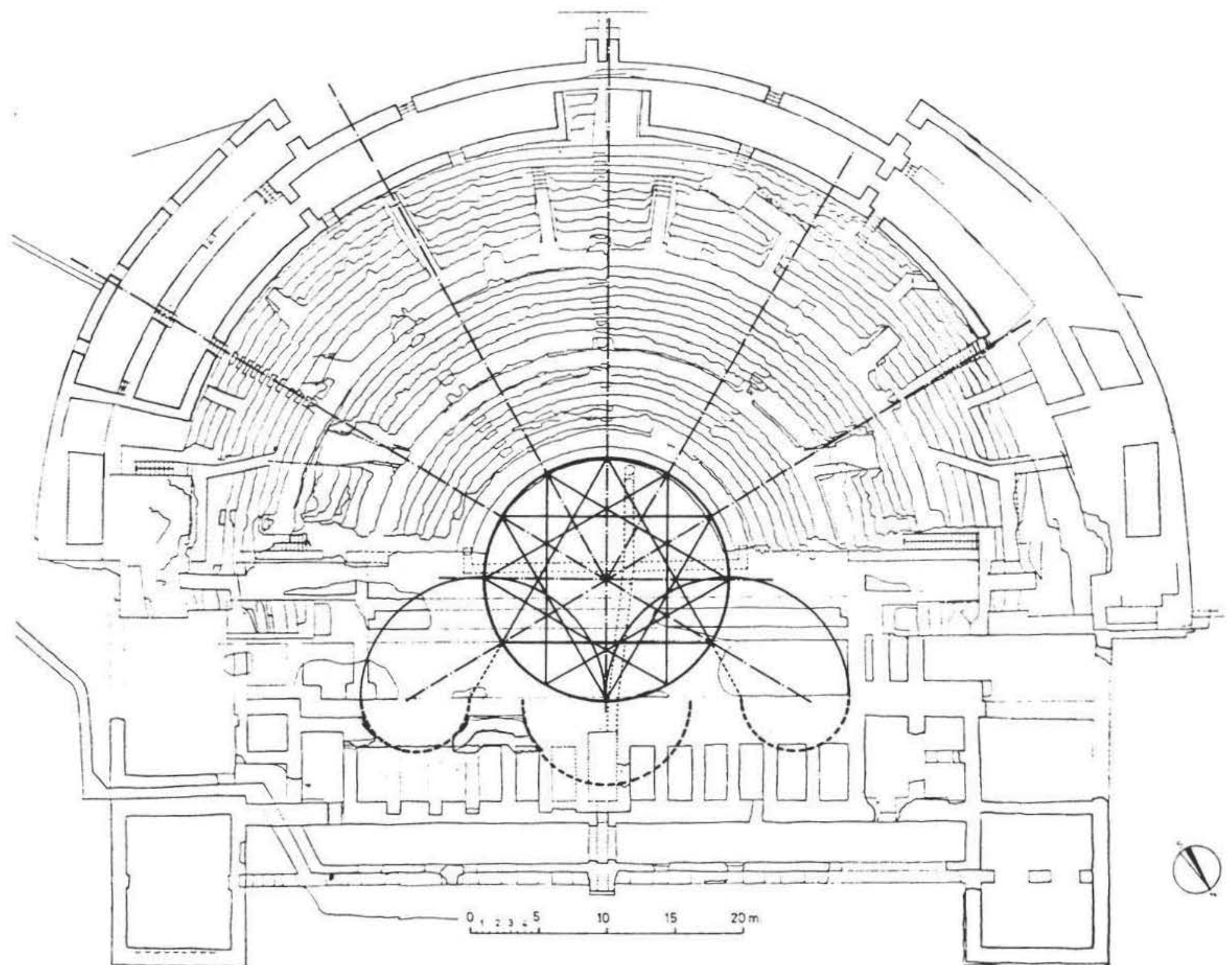

Figura 5.-Teatro de Sagunto. Comparación de los trazados de P. Hammond (1965) y F. Sear (1990). 


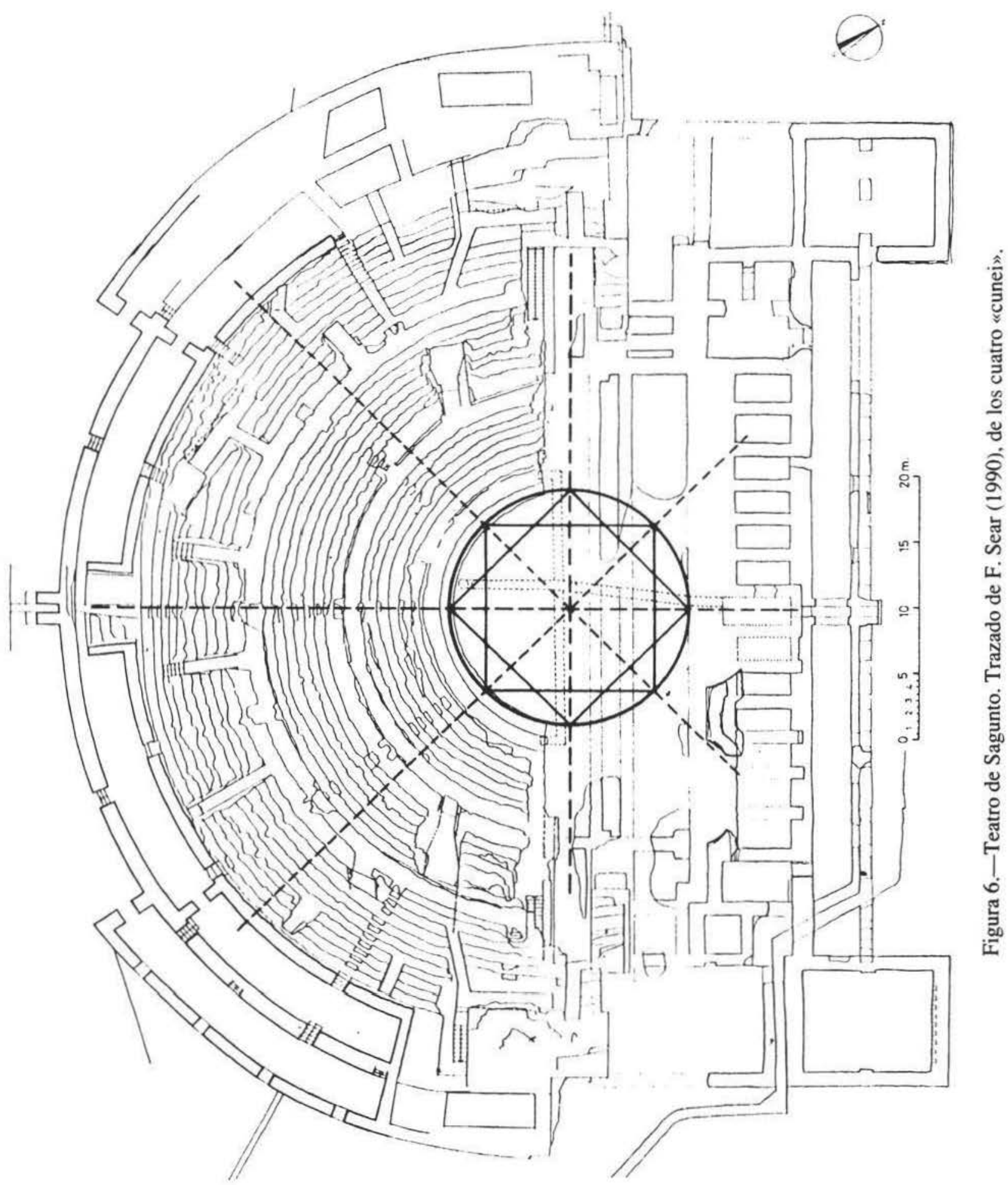




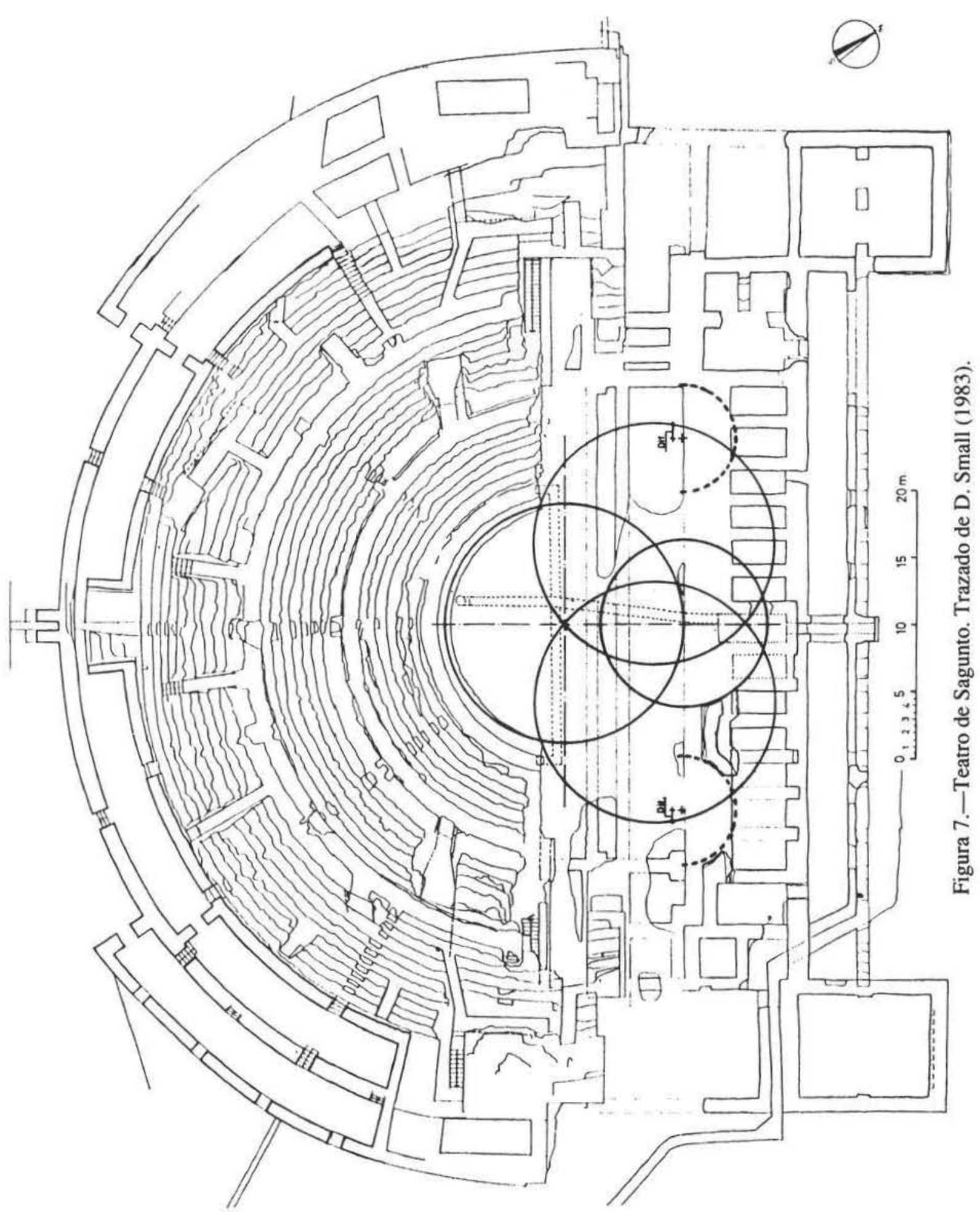


Analicemos los motivos.

Su sistema, a partir de intersección de circunferencias, genera un lugar de puntos en la tangente a la orchestra o muro de frontscaena, con algunas peculiaridades:

En Sagunto, el centro de la circunferencia de la valva regia está en la tangencia, como así sucede habitualmente. Si el diámetro de la valva fuera igual al de la orchestra, el trazado nos llevaría a un punto que coincide con el obtenido por el trazado de F. Sear. En este caso límite los dos trazados coincidirían (ver figura 8). Por lo tanto, pensemos que estamos ante dos caminos diversos que nos llevan a un mismo lugar.

Si aceptamos la limitación del autor de que la valva regia esté comprendida entre 0,46 y 0,81 veces la de la orchestra, su trazado nos define un segmento (b1, b2) sobre la tangente realmente próximo al b3, obtenido por el sistema de triángulos. (Ver figura 9).

Si a esta proximidad le añadimos la dificultad de la exactitud de los trazados en base a la planimetría que utiliza Small y que la tangencia entre la orchestra y escena no siempre es exacta resulta posible alcanzar los puntos deseados, con pequeños ajustes. Los trazados de ambos autores se mueven en un entorno de puntos muy próximos aunque alcanzado por métodos diferentes. Sagunto, es una buena prueba de ello, tal y como se demuestra en las figuras de aplicaciones de los trazados al modelo actual.

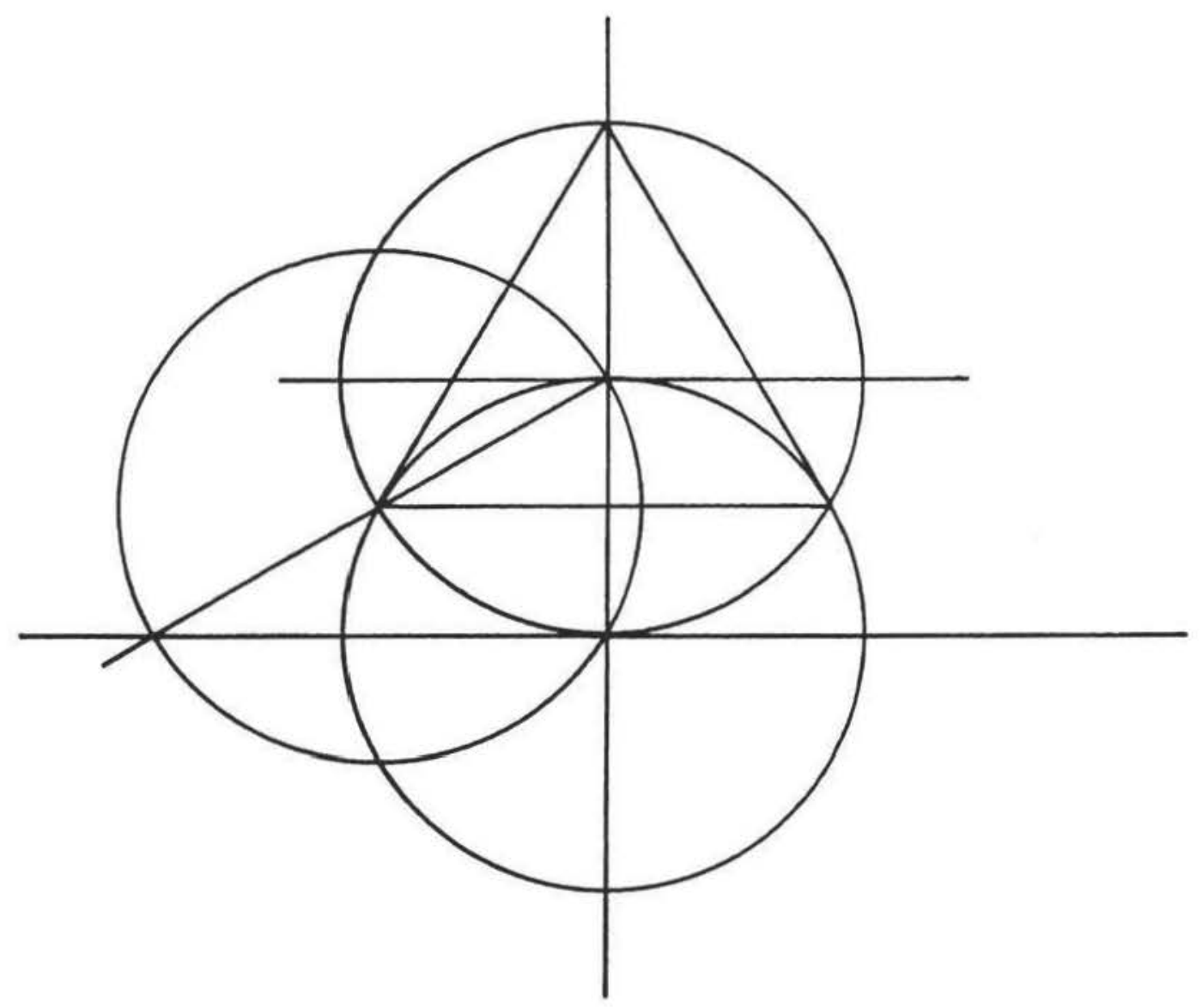

Figura 8. Comparación de los trazados de F. Sear y D. Small. Caso límite, $\phi$ valva $=\phi$ orchestra. 


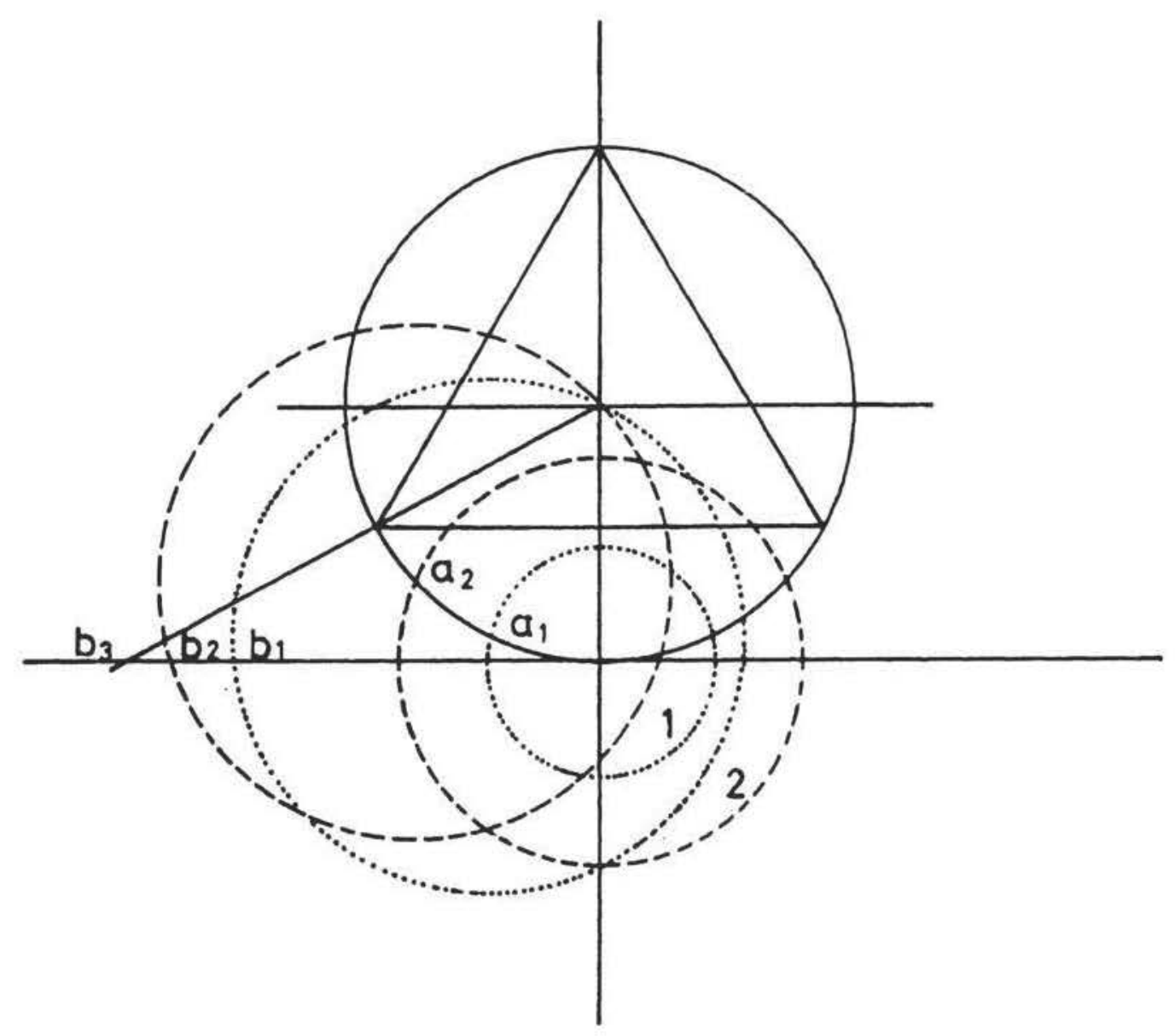

Figura 9.-Comparación de los trazados de F. Sear y D. Small. Límites del autor. Líneas de trazos, $\phi$ max. valva $=0.81 \phi$ orchestra; Líneas de puntos, $\phi \min$. valva $=0.46 \phi$ orchestra.

Hay sin embargo un punto oscuro, no suficientemente explicado en ninguno de los trazados: La posición del frontscaena. Todos los autores detectan que en los ejemplos estudiados se presenta en una posición más retrasada que la que prescribe Vitruvio. Hammond lo situará en una posición intermedia entre la base del triángulo principal y el final de la circunferencia de la orchestra, pero siempre en una posición interior. Ejemplo de esto lo tenemos en Ostia ó Alba Fucens e incluso Pompeya. Small y Sear lo colocan en la tangencia a la circunferencia, aunque en sus estudios encuentran teatros que lo tienen cerca de la tangente pero en puntos interiores a la orchestra y a veces incluso en posición exterior más allá de los límites del círculo. [Sear pág. 253, Small pág. 60].

Esta pequeña arbitrariedad puede ser, al no estar suficientemente precisada, fuente de irregularidad de los trazados. Por otra parte, el replanteo de la tangente a una circunferencia, añade un cierto grado de dificultad en la ejecución. Vitruvio ya había demostrado su habilidad al proponer únicamente para su trazado, circunferencias y triángulos inscritos que constituyen figu- 
ras de muy sencillo trazado y además indeformables y con la ventaja de que la única dimensión recta a utilizar era el radio, una vez para la circunferencia y doce veces para los vértices por medio de una hábil sustitución del trazado de dos hexágonos alternados en lugar de los triángulos, para después restituirlos si fuera necesario.

¿Porqué cambiar los trazados vitruvianos tan avalados por la práctica constructiva de los teatros en Roma? ¿Porqué generar nuevas construcciones geométricas más complicadas y sobre todo inexactas? ¿Porqué desplazar hacia atrás la escena, separando las puertas entre ellas? ¿Quién se atrevería en provincias a plantear diferentes modos de disposición de los elementos del teatro, cuando incluso, como se ha demostrado en Mérida, venían destinados desde Roma canteros y picapedreros?

Si es cierto que, como explican M. Bieber [1916, pág. 186], D. Small [1983, pág. 87] o F. Sear [1990, pág. 258], los teatros en la época de Augusto se debieron plantear con esquemas vitruvianos, y para ello se disponía del tratado; si por otro lado se ha detectado en Hispania que hubo en esta época «un inusitado desarrollo en la construcción de teatros» [Mariner, 1982, pág. 23] y por fin «la planificación romano-imperial de la cima del Castell de Sagunt» [Aranegui, 1985, pág. 246], se hace en época de Augusto, iniciándose después el teatro, debemos concluir la existencia de una primera implantación del teatro saguntino alrededor de la época del cambio de Era. Este extremo ya ha sido demostrado por los sondeos estratigráficos. Además el trazado regulador correspondiente con esta primera implantación, debió de tener una génesis vitruviana, habitual en la época. Sin embargo, hoy presentan las estructuras del teatro un acuerdo mayor con los trazados propuestos por F. Sear e incluso D. Small, que con aquellos del arquitecto romano.

Una clave se presenta como la única con posibilidad de comprensión hacia estas preguntas y suficientemente importante como para darle respuesta a todas: las reformas y ampliaciones y su incidencia sobre la implantación inicial, modificándola. Si en el teatro saguntino, se han reconocido fases, reformas y ampliaciones realizadas sobre su precedente construido y todas ellas en período romano, debe resultar obligado y altamente explicativo indagar alrededor de la estructura formal de cada una de ellas.

\section{FASES CONSTRUCTIVAS Y SUS TRAZADOS RESPECTIVOS}

Del análisis del estado actual del teatro descompuesto en sus diferentes fases y relacionadas con sus correspondientes trazados, se pueden deducir interesantes conclusiones.

Enumeremos las características deducidas del trazado expuesto por F. Sear, aplicándolo al ejemplo saguntino: (figura 6).

- Orchestra sin prima sedes.

- Escena en la tangente paralela a aditi.

- Valva regia en el eje perpendicular.

- Centro de las hospitalia en la intersección, con el muro de escena, de la irradiación de los vértices de la base del triángulo principal.

- Ancho de la escena sin correspondencia con el trazado.

Observemos algunos aspectos interesantes:

El sistema de irradiación de los vértices provoca el mismo efecto, por proporcionalidad, que 
el que se conseguiría por medio de trazados a partir de orchestra concéntricas de diámetro cada vez mayor.

En el caso particular en que la orchestra y el frente de escena son tangentes, los centros de las hospitalia, obtenidos irradiando, coinciden con los vértices de la base de un triángulo principal inscrito en una orchestra de diámetro doble que la original. Si la trazamos en el teatro saguntino esta nueva circunferencia coincide con el balteus de separación entre la primera y segunda praecinctio de la parte baja, y además resulta tangente a la parte trasera del muro de escena. De este modo detectamos la existencia de un posible trazado de ámbito diferente al inicial (ver figura 10).

- Orchestra abarcando la ima cavea hasta la primera praecinctio inclusive (O2).

- Frente de escena en línea con la base del triángulo principal (Tp2).

- Valva regia en el diámetro perpendicular.

- Eje de las hospitalia «enfrente» de los vértices de la base del mismo triángulo principal $\left(\mathrm{H}_{2}\right)$.

- Ancho de la escena sin correspondencia con el trazado.

Las bases vitruvianas de este trazado son obvias y serían exclusivas al suponer:

Primero el desplazamiento de los centros de las hospitaliae de los vértices centrales a los extremos, siempre dentro de los 5 que corresponden a la escena. Esta evolución ya fue explicada por F. Sear en su artículo.

Y segundo una nueva orchestra que considerara todas las gradas de la ima cavea como prima sedes es decir senatoriales. Esta explicación viene avalada por la comunicación entre los aditi y los vomitorios principales creando un único acceso y por la existencia de la doble praecinctio baja y su balteus que separan definitivamente estas gradas del resto de la cávea.

No es de extrañar que para ampliar la cávea se recurra a aumentar el tamaño de la orchestra para que ordenado por el nuevo trazado regulador, el conjunto del teatro crezca también proporcionadamente. Recordemos que Vitruvio deja que el arquitecto elija el diámetro de la orchestra - única variable vitruviana y módulo del conjunto- en función del tamaño que quiera obtenerse del conjunto del teatro.

Se puede detectar una última correspondencia de líneas. El postscaenium edificado en la ampliación, necesario ya que las valvas semicirculares ocupan todo el fondo del edificio escénico preexistente, se sitúa en la tangente a la circunferencia resultante de la doble praecinctio alta.

\section{CONCLUSIÓN TIPOLÓGICA DE LA EVOLUCIÓN}

De acuerdo con los estudios anteriores, se puede deducir el sistema de los trazados que fue aplicado en la evolución del teatro saguntino. Los trazados detectados se apoyan exclusivamente en el modelo vitruviano, es decir, partiendo de los dos elementos básicos: la circunferencia de la orchestra variable del sistema y sus cuatro triángulos equiláteros inscritos. La relación, de los elementos arquitectónicos así resultante en Sagunto es la vitruviana.

La semicircunferencia de la cávea, define las escaleras que, con leves ajustes, parten de la orchestra y el diámetro, la posición de los aditi. La base del triángulo principal se alinea con el frente de escena. Los tres vértices centrales sitúan los centros de las valvas. Hay que recalcar sin embargo, alguna peculiaridad que suponen complementos o modificaciones respecto de lo que sería la pura ortodoxia vitruviana: 


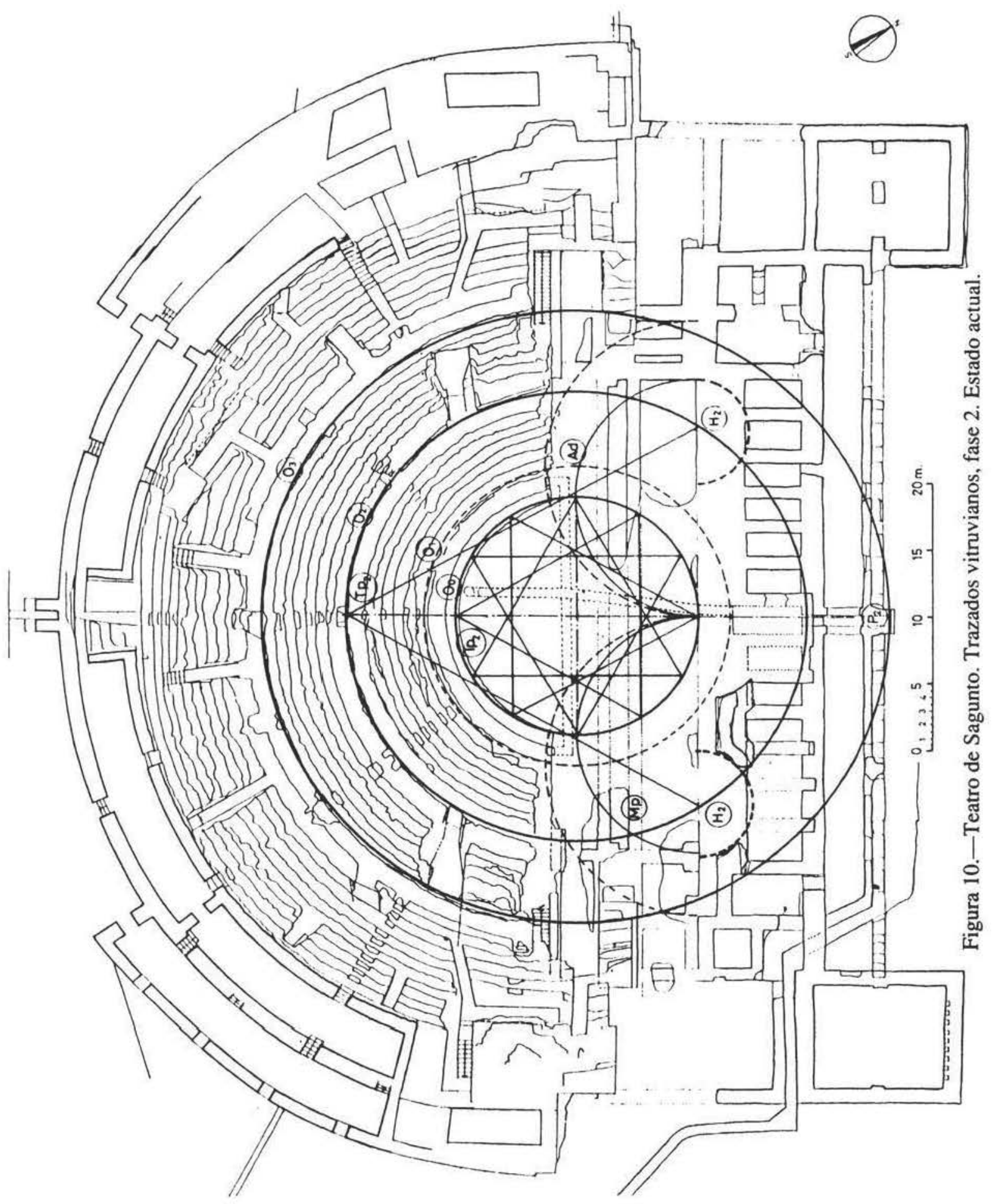


- La variabilidad en la posición del aditus:

Si como en el caso de Sagunto el eje del aditus coincide con el diámetro, el semiancho de éste, absorbe un espacio de la semicircunferencia que después se reparte distribuyendo uniformemente las escaleras y corrigiendo proporcionalmente su posición respecto de los vértices de los triángulos. Esto ya fue explicado por F. Sear [Sear, 1983, pág. 254].

- La aparición del postscaenium:

En la tangencia a la circunferencia de la orchestra, se halla el fondo de la misma parte trasera del muro de escena o postscaenium. Como éste no venía definido en el tratado vitruviano y por lo tanto no estaba dentro de la orchestra, los arquitectos romanos debieron iniciarlo justo donde acababa la circunferencia: en su tangencia.

- La situación de las valvas hospitalia:

Si bien Vitruvio advirtió que su posición fuera «enfrente» de los vértices colindantes a la valva regia, en los intentos de agrandar el edificio escénico, los centros se desplazaron a los vértices contiguos, que por otro lado, no tenían una clara función asignada en el texto romano.

Por un lado la necesidad constante de ampliación de la cávea para aumentar y diversificar el aforo y por otro el agrandamiento de la escena por argumentaciones representativas y de complejidad escenográfica, motivaron la necesidad de evolución de las estructuras teatrales. La respuesta que propuso Vitruvio presentaba dificultades.

Para conseguir un teatro más grande, había que partir de una orchestra mayor y trazar con respecto a ella. Pero esto con el teatro construido suponía graves problemas técnicos y constructivos, ya que hacer aumentar el diámetro de la orchestra, vaciándola, además de perder gradas previamente construidas, suponía la realización de costosas e innecesarias obras de excavación o de rellenos, dependiendo del caso. Por otro lado problemas funcionales ya que todo espacio dedicado a la orchestra era «inútil» en el teatro romano. A diferencia del teatro griego, este lugar no era utilizado por los romanos, ni para espectadores ni para la representación. Su uso se reducía a la tímida disposición de las gradas senatoriales y a permitir el acceso.

Había que buscar otro sistema. La propuesta me parece ahora altamente ingeniosa. Si aumentamos el número de gradas senatoriales, la orchestra crece con ellas. No una orchestra vacía sino ocupada por espectadores importantes. Así, el acceso a la ima cavea, ahora es el mismo que el de la orchestra. Las escaleras transversales de comunicación entre aditi y vomitorios principales son claros testigos de ello, tanto en Baelo o Medellín, como en Sagunto. Sin obras de gran envergadura, aumenta el círculo a voluntad y con ello el trazado regulador hace crecer el frente de la escena, manteniendo la ordenación vitruviana del conjunto.

En Sagunto, el modo de su aplicación es muy didáctico. Para realizar el salto del aumento de la orchestra de la supuesta Fase 0, se alcanza la Fase 2, ambas de trazado vitruviano, pasando previamente por la 1 (ver figura 11).

Fase 0: Trazado ortodoxo vitruviano ya comentado, donde se observan las siguientes líneas de trazado en la figura adjunta.

Oo: Circunferencia sin gradas senatoriales.

Ad: Aditus, diámetro de la orchestra.

FEo: Frente de escena. Valvas sobre vértices centrales (Ho).

Po: Postscaenium. 


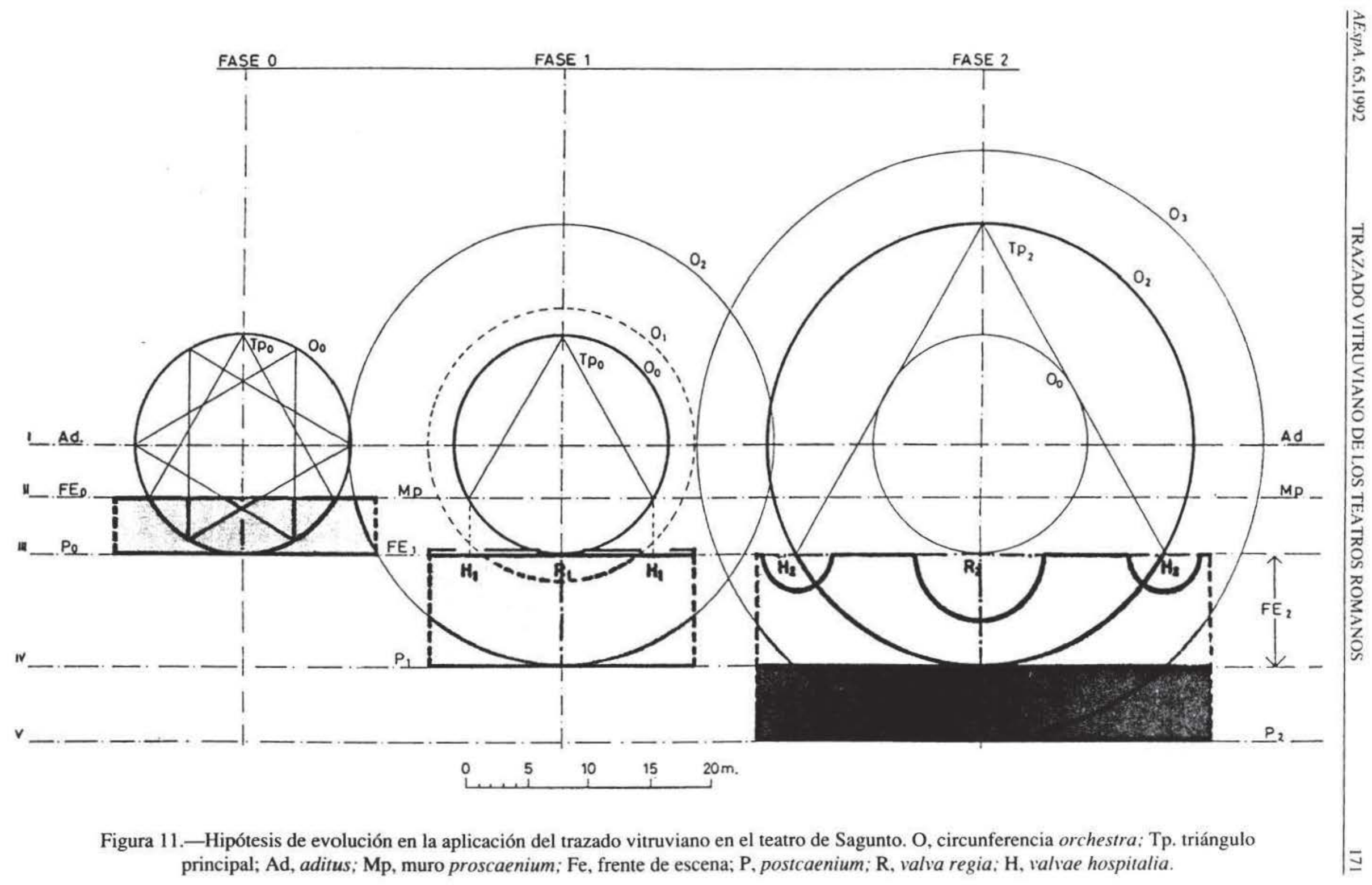


Fase 1: Se retrasa el frente de escena manteniendo la orchestra, con la incorporación de las gradas senatoriales:

Oo: Se mantiene la circunferencia anterior.

Tpo: Triángulo principal anterior.

FE1: El frente de la escena busca el muro del postscaenium (anterior $\mathrm{Po}$ ).

$\mathrm{Pl}$ : Se crea un nuevo postscaenium en la tangente a la $1^{\text {a }}$ praecinctio $(02)$.

$\mathrm{R} 1$ : Se retrasa sobre FE1.

H1: Se amplía el ancho a los vértices de Tpo y se retrasan a FE1.

Mp: El proscaenium ocupa el lugar de la antigua escena en FEo.

Fase 2: Se reordena conjuntamente cávea y escena según el trazado vitruviano:

02: Nuevo diámetro de orchestra. Incorpora la ima cávea.

Tp2: Nuevo triángulo principal inscrito.

FE2: Nuevo frente de escena rediseñando el anterior (FE1) y ocupando el anterior espacio del postscaenium hasta P1.

$\mathrm{P} 2$ : Nuevo postscaenium en la tangente a la $3^{\mathrm{a}}$ praecinctio $(03)$.

$\mathrm{R} 2$ : Aparece la valva regia semicircular.

$\mathrm{H} 2$ : Hospitalia sobre los vértices de Tp2.

Veamos un cuadro resumen del conjunto:

\begin{tabular}{|cccc|}
\hline LINEA & FASE 1 & FASE 2 & FASE 3 \\
\hline I & Aditus & Aditus & Aditus \\
\hline II & Frontscaena & Proscaenium & Proscaenium \\
\hline III & Postcaenium & Frontscaena & Frontscaena \\
\hline IV & - & Postcaenium & Scaena \\
\hline V & - & - & Postcaenium \\
\hline
\end{tabular}

Observamos que los tres trazados producen doce alineaciones diferentes (tres el primero, cuatro el segundo y el cinco el tercero) que se colocan en un total de cinco líneas por lo que cada nuevo trazado se produce reutilizando los muros anteriores y creando uno nuevo correspondiente al postscaenium. El sistema es altamente ingenioso, ya que consigue de un sólo golpe solucionar diferentes y contradictorios problemas.

- La reutilización de estructuras precedentes por la cual ningún muro se queda descolgado del trazado.

- Se crean nuevas edificaciones siempre en la parte trasera de la cávea y postscaenium, por lo que de este modo sería posible también la redecoración de fachadas con cada reforma.

- Supone una reinterpretación del concepto de orchestra como el área baja dedicada a las primas sedes, más acorde con el concepto romano no destinado a la representación sino a la expectación y por ello localizado en el semicírculo de la cávea. 
- La relación entre el postscaenium y su tangencia a las circunferencias de las praecinctio de la cávea sigue manteniendo la relación de unidad entre cávea-escena tan definitoria del teatro romano.

- Cualquier reforma o ampliación era reutilizable para las otras siguientes fases que se pudieran producir. Sin más que extender la orchestra hasta la siguiente praecinctio se generaba el nuevo trazado a aplicar. Bien es verdad que cada vez el desarrollo se complicaría más debido sobre todo a que el ensanchamiento de la escena obligaría a distanciar los aditi para facilitar la visión.

El trazado vitruviano fue mantenido siempre como el sistema generador del conjunto del edificio teatral durante el tiempo de duración de la cultura romana. Suponer que esto no fue así, no explicaría las similitudes tan profundas entre los teatros del imperio. Si teatros tan distantes y de épocas tan diferentes como Aspendos, Sabratha, Dougga, Amman, Pompeya o Sagunto se pueden utilizar como modelos comparables entre sí hasta un grado muy elevado de similitudes tuvo que ser debido a algo más que casualidades. El «Orden Romano» y Vitruvio como su ejemplo más directo y pragmático debieron ser sus causas. El análisis del teatro romano de Sagunto así se lo reconoce.

\section{CONTRASTACIÓN CON OTROS DE HISPANIA}

Una vez identificados los trazados reguladores que coordinaron el desarrollo y ampliación del teatro de Sagunto, la propuesta, aquí presentada, debería ser contrastada. Se debería estudiar la posibilidad de su generalización por medio de la efectividad o no de su aplicación en otros teatros, aunque ello conlleva algún impedimento previo que sería deseable superar.

La primera dificultad surge por la inexistencia, de un modo generalizado, de cartografía adecuada de los teatros para la realización de una investigación que precisa tanta exactitud como ésta en Hispania. Itálica, Segóbriga y Sagunto son las excepciones a esta desafortunada norma y que todos deben su existencia, directa o indirectamente, al magisterio de Antonio Almagro Gorbea. Del treatro de Acinipo se dispone de planos que, sin llegar a ser del todo precisos, si permiten alguna aproximación. Al respecto del teatro de Mérida sería imprescindible para avanzar en cualquier línea de investigación sobre sus interesantes estructuras, reelaborar su cartografía dadas las inexactitudes que presentan los planos de 1963. De la mayoría, sin embargo, disponemos de simples croquis muchas veces realizados durante las excavaciones (Baelo, Clunia, Regina, Medellín, Málaga, etc.).

La segunda dificultad se presenta porque su realización precisa necesariamente de un análisis previo en detalle de cada uno de los teatros que abarque tanto la cávea como la escena. Es necesario tener claro una exacta división de los distintos órdenes por medio de la localización de sus praecinctio y respectivos balteus, para determinar los sucesivos ámbitos de la orchestra. El edificio escénico debe demostrar con suficiente claridad las distintas etapas históricas que ilustran su construcción. Las posiciones de sus elementos principales (línea de frente de escena, muro de proscaenium, valvas regia y hospitalia e incluso la alineación del postscaenium), deben poderse reconocer aisladamente y como partes integrantes del conjunto.

Por otro lado, es conveniente distinguir previamente la existencia de las diferencias que generaron el diferente grado de desarrollo al que llegaron las diversas estructuras teatrales. Así nos apa- 
recen teatros poco evolucionados donde no es fácil detectar ampliaciones o reestructuraciones, probablemente porque no existieron, junto con otros altamente transformados como el caso saguntino. A esto debemos superponer la diferencia cronológica en el momento de su fundación. Los teatros tardíos sin duda fueron menos modificados que los más antiguos y su inicial implantación debió ser diferente, como diferente era el gusto de la época y mayor la experiencia acumulada.

\section{ITÁLICA}

A partir de la reciente planimetría elaborada por Alfonso Jiménez, quizá la más completa existente de cualquiera de los teatros de Hispania se detectan las correspondencias siguientes: (ver figura 12).

Orchestra $1(0.1)$. Trazado vitruviano original.

- Circunferencia de la orchestra coincidiendo con el bisellium. (0.1).

- Eje de los aditi sobre el diámetro (AB).

- Línea del proscaenium sobre base del triángulo principal (T.1).

- Frontscaena en la tangente a la orchestra (Tg.1).

- Muros de subestructura de escena al doble de la orchestra (M.1-M.2).

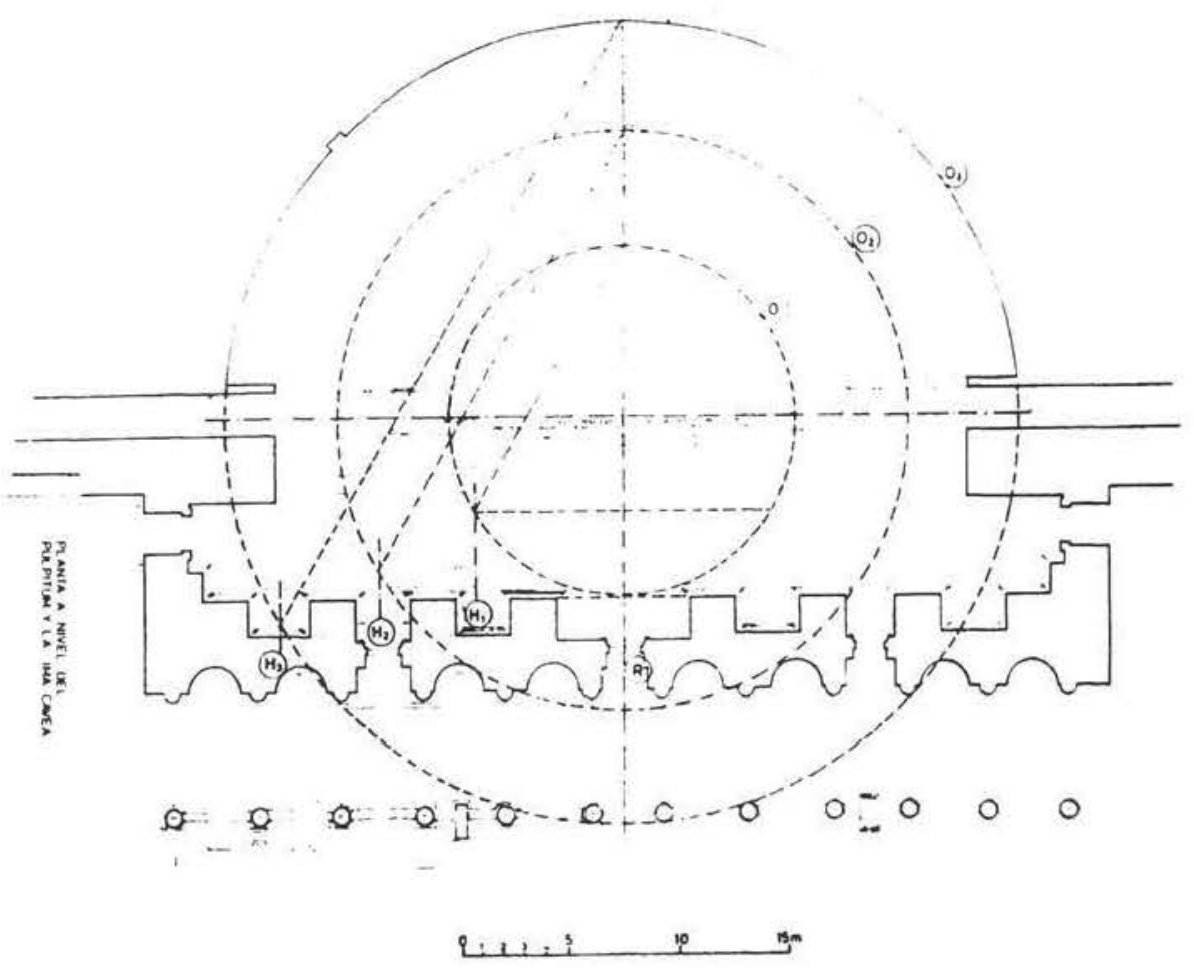

Figura 12.-Teatro romano de Itálica. Ensayos de trazados. 
Orchestra 2 (0.2). Ampliación.

- Circunferencia de la orchestra ( 0.2 ampliada a dos gradas de la ima cavea, allí donde aparecen claramente indicadas las improntas de un balteus para distinguirlas del resto.

- Postscaenium sobre la tangencia (Tg. 2), a la circunferencia (0.2).

- Las valvas hospitalia enfrente de los vértices del triángulo principal (T.2) de la nueva $o r$ chestra (0.2).

- Frontscaena, proscaenium y valva regia sin cambios en su alineación.

Orchestra 3 (0.3). Posibilidad de crecimiento.

- Circunferencia de la orchestra hasta abarcar toda la ima cavea. (0.3).

- Triángulo principal (T.3) plantearía la posibilidad de retrasar algo la escena.

- Pórtico trasero tangente (Tg.3) a la circunferencia resultante de este modo.

Hipótesis de desarrollo:

Si aceptáramos la evolución detectada para el teatro saguntino como extrapolable al caso de Itálica, ello supondría:

Fase 1: Trazado ortodoxo vitruviano (1 $1^{\mathrm{er}}$ planteamiento).

- Frontscaena sobre el actual proscaenium.

- Postscaenium sobre actual frontscaena.

- Valvas hospitalia (H.1) sobre nichos contiguos a la regia.

Fase 2: Ampliación de escena y ámbito de la orchestra.

- Frontscaena en la tangente de la antigua orchestra. Aparición del proscaenium y pulpitum.

- Ampliación de las prima sedes a dos filas de la ima cavea.

- Construcción del postcaenium y sus hexedras.

- Valvas hospitalia (H.2) sobre los vértices del nuevo triángulo principal (T.2).

Previsión de Fase 3: Ampliación de la orchestra a toda la ima cavea. Ello conllevaría la posibilidad de:

- Mantener el lugar del frontscaena o retrasarlo una distancia muy pequeña. Si se procediera igual que en Sagunto la posición quedaría invariable.

- Desplazar las valvas hospitalia (H.3)un nuevo nicho hacia el exterior sobre los vértices de la nueva base del triángulo principal (T.3).

- La ocupación del espacio cubierto del porticus trasero para ser utilizado como postscaenium, función que ya desempeñaba.

Esta última fase que no llegó a realizarse, sí estaría prevista al terminar la Fase 2, para lo cual se hicieron corresponder las posiciones de los elementos con el nuevo trazado derivado de (0.3). A la vista de estas hipótesis resulta sugerente profundizar en las similitudes con la evolución del teatro saguntino. 


\section{SEGÓBRIGA}

En base a la restitución de A. Almagro que presentó para el Simpósium de Mérida [Almagro, 1982, pág. 29], se pueden detectar las siguientes correspondencias (ver figura 13).

Orchestra l. Trazado vitruviano modificado.

- Circunferencia de orchestra con límite en el bisellium.

- El diámetro AB no separa la cávea de la escena sino marca con bastante exactitud las versurae.

- Los aditi sitúan su eje sobre la base CD del triángulo principal invertido ocupando espacio destinado tradicionalmente a la cávea.

- Las escaleras regia y laterales tienen marcada su posición por los vértices resultantes en la porción de la circunferencia que ocupa la cávea.

- El frontscaena se alinea con la base del triángulo principal dentro de la ortodoxia vitruviana.

- El postscaenium se alinea en la tangente a la circunferencia $(0.1)$ de la orchestra inicial.

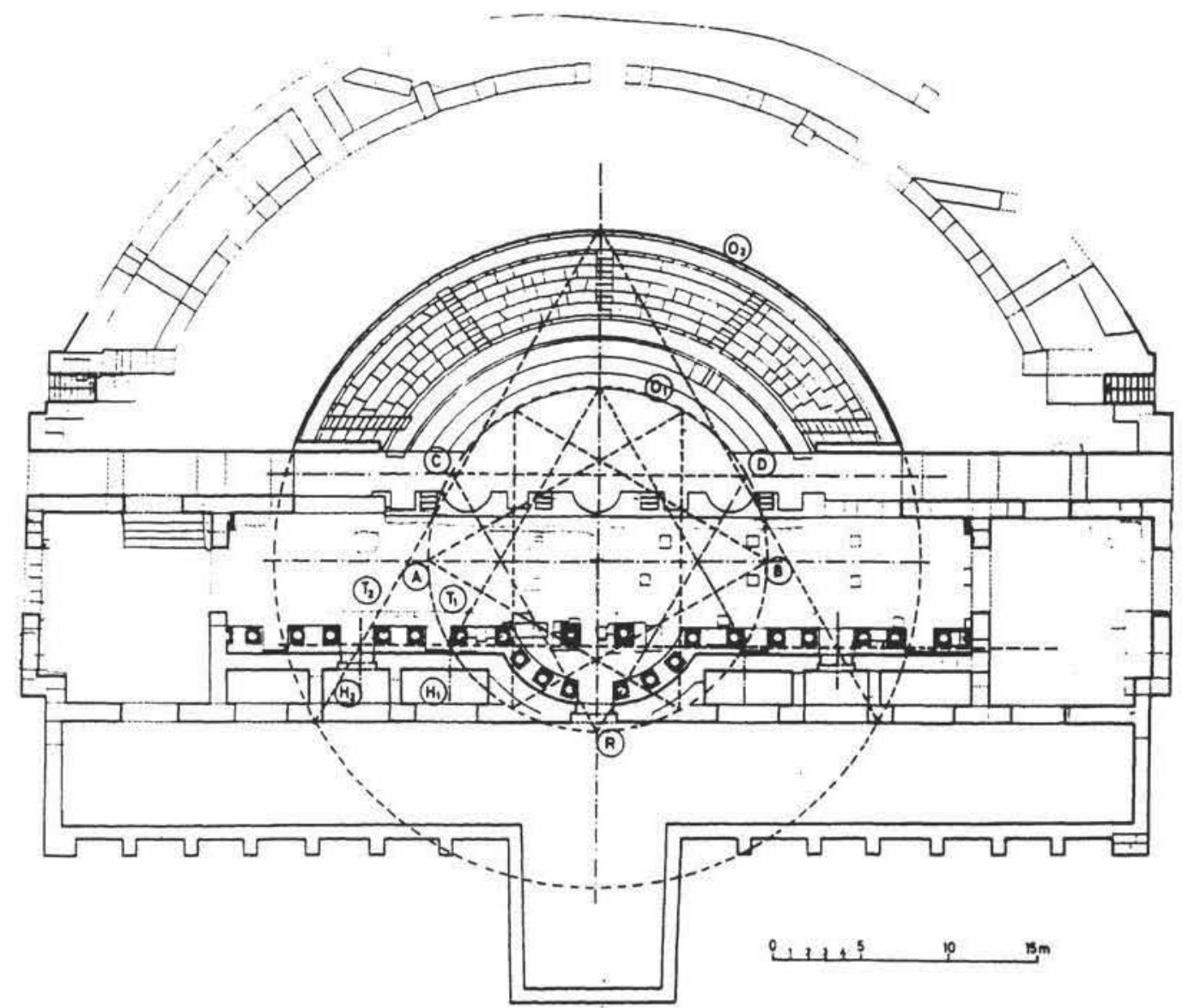

Figura 13.-Teatro romano de Segóbriga. Ensayos de trazados. 


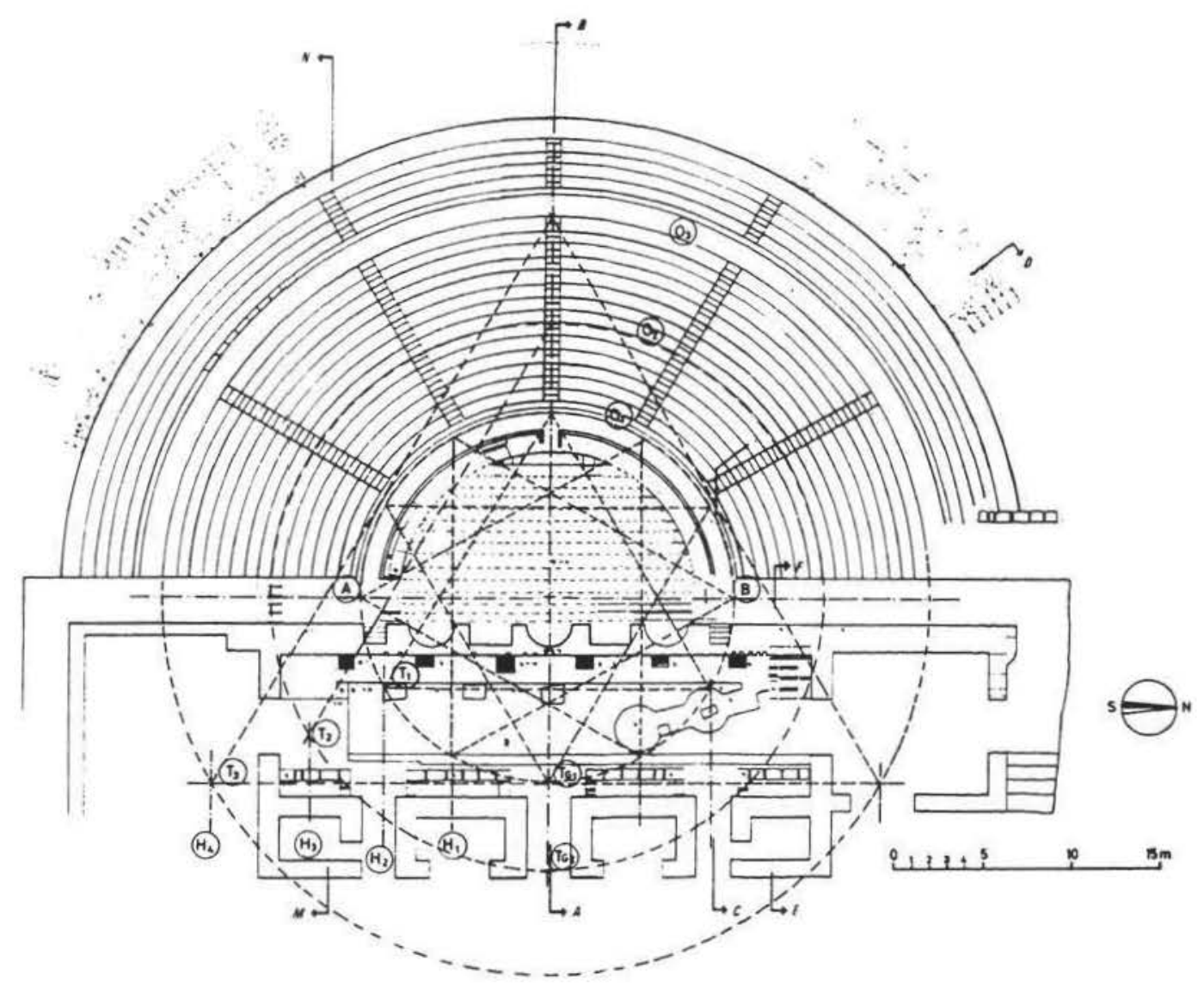

Figura 14.-Teatro romano de Acinipo. Ensayos de trazados.

Orchestra 2 (0.2): Posibilidad de crecimiento.

- Circunferencia (0.2) definida por la ocupación de la ima cavea por la orchestra.

- Base del nuevo triángulo principal (T.2) sobre la alineación del postscaenium prexistente, donde se situaría el nuevo frontscaena.

- Valvas hospitalia definidas por la intersección del nuevo triángulo T.2, con la anterior frente escena.

- Nuevo postscaenium sin relación aparente con el trazado.

Hipótesis de desarrollo:

Fasel: Trazado vitruviano modificado.

Partiendo del trazado ortodoxo pero modificando la relación de los vértices con los elementos. Así el arquitecto trasladó los ejes de los aditi a los vértices contiguos en la direćción de la cávea. Esta propuesta hábilmente innovadora conseguía reducir el espacio ocupado por la gradas para que no alcanzaran el semicírculo, dando gran capacidad al edificio escénico. 
Por otro lado. los laterales de la cávea en su encuentro con las parascaenia, que eran espacios de muy deficiente visibilidad por estar en posición paralela a la escena se ven reducidos así. Nos encontramos ante una nueva reinterpretación del trazado vitruviano, demostrándose otra vez que esto debía ser moneda común de los arquitectos romanos, preferentemente, en épocas tardías, como la de Segóbriga.

Fase 2: Posibilidad de crecimiento.

Si se produjera la ampliación con el consiguiente retraso del frontscaena para ocupar la línea del postcaenium esta coincidiría con la base del nuevo triángulo principal (T.2), volviendo a responder a un trazađo vitruviano. Esto no llegó a producirse. Sí se realizó sin embargo una redecoración de escena a finales del siglo II o principios del III [Almagro, 1982, pág. 35] que afectó a la posición de las valvas. Se realizó en hexedra la valva regia y las hospitalia debieron de alejarse de su inicial posición $\mathrm{H} 1$ a la $\mathrm{H} 2$ intersección del nuevo triángulo principal T.2 con el existente frente de la escena que no se retrasó.

\section{ACINIPO}

Si creemos en la cronología propuesta por M. del Amo en su ponencia del Simposium de Mérica, [Del Amo, 1982, pág. 230], nos hallamos ante uno de los teatros más antiguos de His-

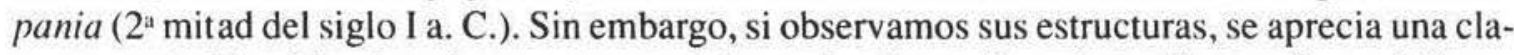
ra conceptualización vitruviana que supondría una implantación más tardía (ver figura 14).

Orchestra (0.1). Trazado vitruviano evolucionado.

- Circunferencia de la orchestra desde la ima cavea.

- Eje de los aditi sobre el diámetro A.B.

- Proscaenium sobre base del triángulo principal (T.1).

- Frontscaena sobre la tangente $\mathrm{Tg}$ a la orchestra $(0.1)$.

- Hospitalia (H.2) enfrente de los vértices de la base del triángulo principal.

- Scalaria de la cávea en número y posición vitruvianas, con la corrección del eje del aditus.

Dada la exactitud de este trazado habría que estudiar la posibilidad de una primera implantación de escena sobre el actual proscaenium y la posición de las valvas recayendo en (H.1).

La actual ima cavea tiene 14 gradas, como el original trazado saguntino, pero aparentemente carece de praecinctio. Sin embargo se detecta una grada - la $7^{\text {a }}$ o intermedia - que se sitúa sobre una circunferencia (0.2) que coincide con el arranque de las bóvedas de los aditi y es tangente al postcaenium de acuerdo con los trazados generales estudiados. De poderse confirmar este extremo, la cávea baja y el trazado de Acinipo presentaría una similitud muy ajustada con la primera implantación del teatro saguntino y su adaptación del modelo vitruviano.

En cualquier caso, resulta difícil pensar en la fundación del teatro de Acinipo en una etapa anterior a la llegada del sistema de definición del trazado vitruviano a España, dadas las múltiples y exactas correspondencias que presenta con él.

Orchestra (0.2). Vinculada a la demostración de la praecinctio del punto anterior, su uso supondría el desarrollo genérico del modelo vitruviano. 
- Circunferencia (0.2) abarcando la parte inferior de la ima cavea.

- Frontscaena en la tangencia a (0.1) sin cambios.

- Alteración posible de las hospitaliae de (H.2) a (H.3) sobre la invariable tangencia de la scaena.

Orchestra (0.3). Mayor ampliación futura.

- Circunferencia (0.3) hasta la praecinctio alta, absorbiendo la orchestra toda la ima cavea actual.

- No se detectan tangencias a falta del futuro postscaenium.

- La base del triángulo principal (T.3) coincide con la actual posición del frontscaena, reafirmando a la ortodoxia vitruviana.

- Los vértices de la base de T.3 definen los centros de las actuales puertas de la parascaenia (H4). Una futura ampliación ocuparía para la escena estas habitaciones laterales.

Únicamente he pretendido plantear, de algunos teatros de los que dispongo de cartografía suficiente, una serie de correspondencias geométricas entre sus partes que sin llegar a ser eficaces trazados reguladores, si creo que transcienden lo que sería la mera casualidad. Desarrollar esta línea de trabajo lo considero altamente interesante y explicativo de la realidad de las estructuras teatrales, al tiempo que, a mi entender, hay encerrada en la propuesta una gran potencialidad de conocimiento para el futuro de los teatros. Con esta confianza concluyo.

\section{BIBLIOGRAFÍA}

Almagro, Martín y Antonio: El Teatro romano de Segóbriga. Actas del Simposium «El Teatro en la Hispania Romana Mérida», 1982.

ARANEGUI, C. y otros: La data de construcció del teatre romá de Sagunt. Barcelona, 1985. BIEBER, MARGARET: The History of the Greek and Roman theater. New Yersey, 1961.

Del Amo, Mariano: El Teatro romano de Acinipo. Actas del Simposium, «El Teatro en la Hispania Romana». Mérida 1982.

Hammond, P. C.: The excaration of the main theater at Petra. London, 1965.

HANSON, JHON A.: Roman Theater-Temples. Princeton, 1959.

MARINER BIgORRA, Sebastiaín: «El teatro en la Hispania Romana». Mérida, 1982.

SEAR, FRANK B.: "Vitruvius and Roman Theater Design" Adelaida, 1990.

SMALL, DAVID B.: «Studies in Roman Theater Design». Cimbridge. 1983. 